\title{
Profile of Risk Factors Associated with Stillbirth at Western Regional Hospital
}

\author{
Regmi Rabi Prasad ${ }^{1 *}$, Parajuly Shyam Sundar ${ }^{2}$, Singh Dela ${ }^{1}$, Shrestha Nabin ${ }^{1}$, Sharma Srijana ${ }^{1}$, \\ ${ }^{1}$ Department of Obstetrics and Gynecology, Pokhara Academy of Health Sciences ,Western Regional Hospital, \\ ${ }^{2}$ Department of Radiology, Pokhara Academy of Health Sciences, Western Regional Hospital
}

\section{*Corresponding Author}

Dr. Rabi Prasad Regmi, MD

Senior Consultant,

Department of Obstetrics and Gynecology, Pokhara Academy of Health Sciences, Western Regional Hospital, Pokhara

Email: drraviregmi@gmail.com

Article received : February 27, 2018

Article accepted : March 27, 2018

\begin{abstract}
Background: Stillbirth (SB) incidents are one of the most common adverse outcomes to occur during pregnancy. Studies indicate that approximately 3.3 million stillbirths are reported annually across the developing world. Institutional registration and under reporting of still birth to an authorized centre is a common problem. Objective: The objective of this study is to find out the incidence of SB after 28 weeks gestation and to find out the associated risk factors at Western Regional Hospital of Nepal. Materials and Methods: This is a cross sectional study carried out at Western Regional Hospital. Stillbirth babies born after 28 weeks of gestation or birth weight $\geq 1$ kilogram and their mothers were recruited for the study. Intrapartum stillbirths were included despite of their ages, races or socioeconomic status. Descriptive analysis was done on the data. Results: There were 3380 deliveries during the period of study. Among them, 50 cases were stillborn babies with a rate of 14 per thousand deliveries. The major risk factors associated were oligohydramnios, decreased fetal movement, growth restriction, meconium stained liquor and cord prolapse. Conclusion: Oligohydramnios (amniotic fluid index $<5 \mathrm{~cm}$ ) was the most common risk factor for stillbirth. Early identification and appropriate perinatal management could help to promote perinatal health.
\end{abstract}

Keywords: Stillbirth, antepartum, growth restriction, macerated.

\section{INTRODUCTION}

Stillbirth (SB) incidents are one of the most common adverse outcomes to occur during pregnancy. Studies indicate that approximately 3.3 million stillbirths are reported annually across the developing world. ${ }^{1-2}$ Stillbirth is not only associated with physical and psychological morbidity, but can also remain a significant source of cost for the affected family and community. ${ }^{3}$ Many factors can lead to stillbirth, most prominent of which include: congenital infections such as syphilis, malaria, and other maternal acute infections, birth injuries, preeclampsia, eclampsia, poor nutritional status, previous stillbirth, congenital anomaly, and sickle cell disease. ${ }^{4}$ Based on a study by Lawn et al., the reported incidence of still birth after 28 weeks has been found to be 5-40 cases per 1,000 births based on various factors such as: geographic regions, socio-economic conditions, and the country's development. ${ }^{5}$ Research based on Nepal indicated that about $50 \%$ of the total number of stillbirth occurs during the intrapartum period. ${ }^{6}$ Stillbirth is a common dilemma faced by many people in the world. Given the prevalence of stillbirth and the negative impact that it can have on the family, it is necessary that the medical community find all preventable measures that can be taken in stillborn cases. Although some risk factors have commonly been recognized in the past, not many studies have attempted to quantify precisely how/what factors can be connected to stillborn conditions. Given that only a handful in-depth profiling and analysis regarding stillborn conditions have been conducted, it becomes obvious that more research in this field is necessary.

World Health Organization defines stillbirth as a birth weight of at least 1000 grams or a gestational age of at least 28 weeks. $^{7}$ The majority of stillbirths worldwide (98\%) happen in low and middle-income countries, where medical care can be of low quality or unavailable. ${ }^{8}$ Stillbirths can be categorized as either antepartum (i.e. occurring before the onset of labor) or intrapartum (i.e. occurring after the onset of labor and before birth). When there is no fetal monitoring to confirm the presence of 
a fetal heart rate at the onset of labor, assessment of the skin appearance is frequently used to estimate the timing of the stillbirth. ${ }^{7}$ Signs of skin maceration begin around 6 hours after fetal death; therefore, a "fresh" or "non-macerated" appearance of the skin is used as a surrogate measure for an intrapartum stillbirth, whereas a "macerated" appearance is judged as an antepartum stillbirth. However, this assessment may underestimate the rate of intrapartum stillbirths, especially in situations where access to care is delayed. ${ }^{8}$

\section{MATERIALS AND METHODS}

This is a hospital based cross-sectional study done at Western Regional Hospital, Pokhara Academy of Health Sciences (PoAHS). Approval for the study was taken from the institutional review committee (IRC) of PoAHS. Verbal informed consent was taken from the participant. Women who gave birth to stillborn after 28 weeks of gestation or birth weight $\geq 1$ kilogram at WRH were recruited for the study. This cut-off of 28 weeks were enrolled as per World Health Organization definition for still birth. ${ }^{7}$ Each woman was studied on an individual basis. The questions were designed so that their socio-economic condition, education, occupation, previous medical and obstetrics history, can be assessed to determine if any of these factors play a role in her stillbirth. Further, medical and laboratory examinations as hemoglobin level, blood grouping and $\mathrm{Rh}$ typing, VDRL, HIV, HBSAg, random blood sugar and routine examination of urine were analyzed. The study was conducted from $1^{\text {st }}$ October 2017 to $25^{\text {th }}$ January 2018.

Data entry was done in Microsoft Office Excel 2007 version. Collected data were analyzed by SPSS 17 software. Frequency tabulations of still birth were calculated and associated risk factors and predictors were calculated and analyzed on descriptive way.

\section{RESULTS}

There were 3380 deliveries in four months study period, 50 of them were stillborn with a rate of 14 per thousand births. Mothers who gave birth to stillborn babies were 17-40 years old with the mean age of 26.72 years. There were fourteen mothers who were above 30 years old. 33 mothers belonged to rural areas (66\%) and 17 mothers from urban areas (34\%). 38\% of the mothers belonged to low income group and $32 \%$ with high income group (figure 1).

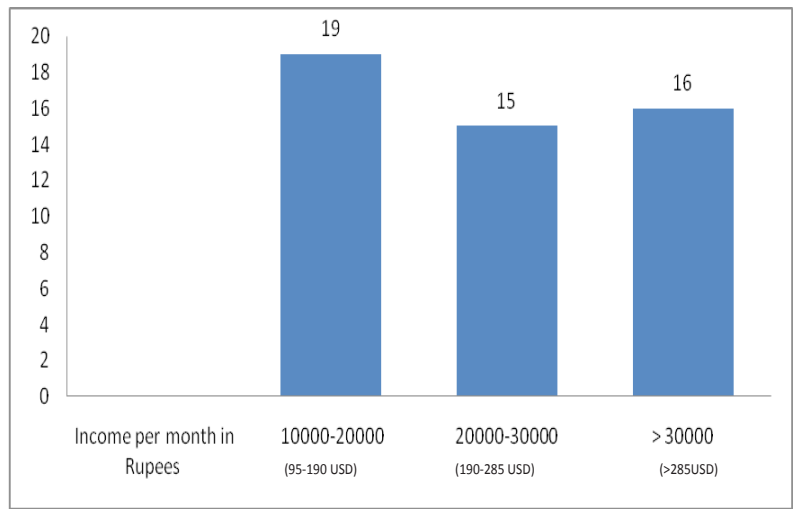

Figure 1 Family economic status of mother

Majority of mothers visited regularly for ANC check up. One case visited 8 times and three cases didn't attend for ANC check up even for a single visit (Figure 2).

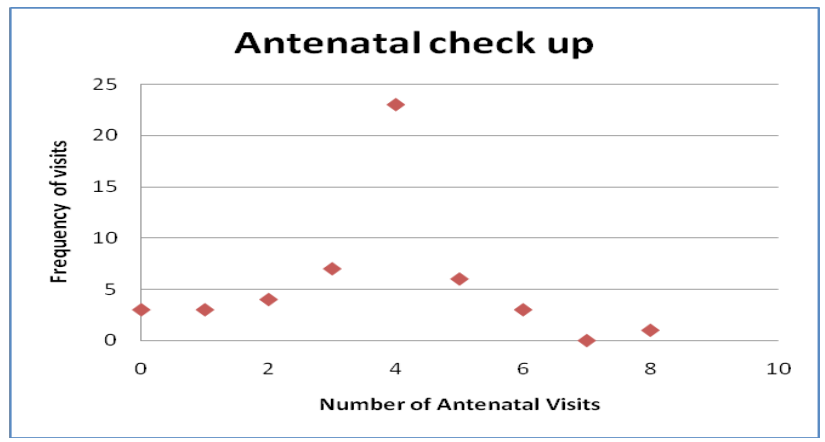

Figure 2. Frequency of ANC visit

There were 41 cases of stillbirths who were born prematurely (Figure 3 ).

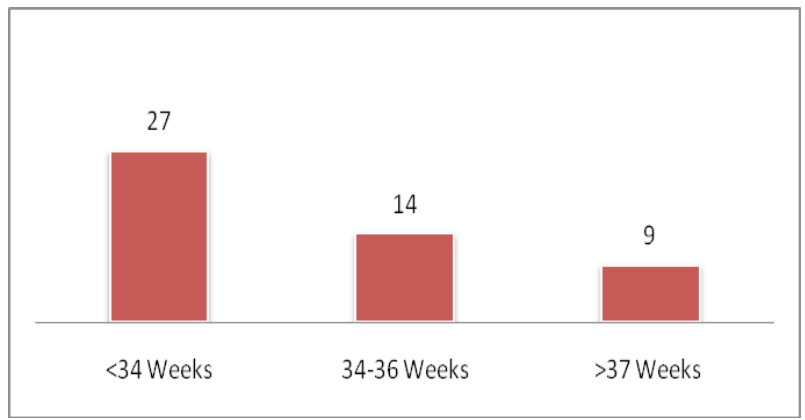

Figure 3. Gestational weeks of SB babies

Of the fifty stillbirths, $30(60 \%)$ were macerated and $20(40 \%)$ were fresh. Fetal related complications were 32 (62\%), placental related $12(24 \%)$ and maternal related $7(14 \%)$ as stated in figure 4 and Table 1-3. 


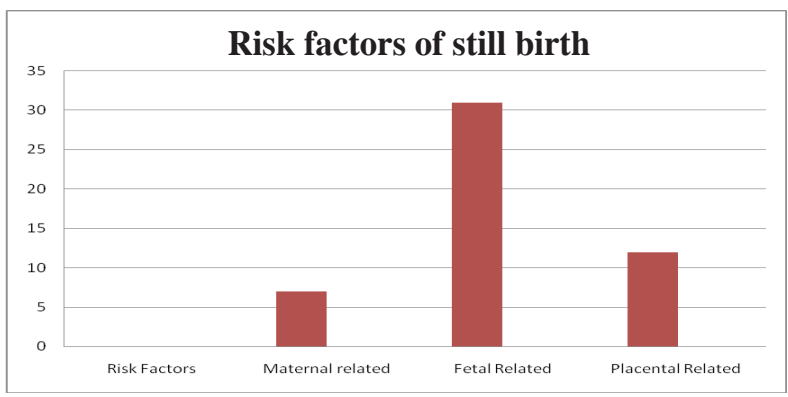

Figure 4. Risk factors classification

Table 1 Maternal risk factors:

\begin{tabular}{|lcc|}
\hline Risk Factors & Frequency & Percentage \\
\hline Pregnancy induced hypertension & 2 & $4 \%$ \\
\hline Maternal chest infection & 1 & $2 \%$ \\
\hline Abnormal Labor (Obstructed Labor) & 1 & $2 \%$ \\
\hline Post term pregnancy (>42 weeks) & 1 & $2 \%$ \\
\hline $\begin{array}{l}\text { Maternal chromosomal abnormality } \\
\text { (Achondroplasia) }\end{array}$ & 1 & $2 \%$ \\
\hline Scar tenderness & 1 & $2 \%$ \\
\hline Total & 7 & $14 \%$ \\
\hline
\end{tabular}

Table 2. Fetal risk factors

\begin{tabular}{|lcc|}
\hline Risk Factors & Frequency & Percentage \\
\hline $\begin{array}{l}\text { Severe congenital anomaly } \\
\text { (Oesophageal atresia) }\end{array}$ & 2 & $4 \%$ \\
\hline Oligohydramnios & 13 & $26 \%$ \\
\hline Rh incompatibility & 1 & $2 \%$ \\
\hline Growth restriction & 6 & $12 \%$ \\
\hline Decreased fetal movement & 9 & $18 \%$ \\
\hline Total & 31 & $62 \%$ \\
\hline
\end{tabular}

Table 3. Placenta related risk factors

\begin{tabular}{|lcc|}
\hline Risk Factors & Frequency & Percentage \\
\hline $\begin{array}{l}\text { Ante partum hemorrhage (APH) } \\
\text { (Placenta previa and abruptio placenta) }\end{array}$ & 2 & $4 \%$ \\
\hline $\begin{array}{l}\text { Cord accident } \\
\text { (Cord prolapse, cord around the neck) }\end{array}$ & 4 & $8 \%$ \\
\hline PROM & 1 & $2 \%$ \\
\hline Meconium stain liquor & 5 & $10 \%$ \\
\hline Total & 12 & $24 \%$ \\
\hline
\end{tabular}

Among the all risk factors stated, oligohydramnios was the leading cause for stillbirth (26\%) followed by decreased fetal movement (18\%), growth restriction (12\%), thick meconium stain liquor (10\%) and cord accident (8\%). Pregnancy induced hypertension, APH and congenital anomaly contribute $4 \%$ each. Obstructed labor, scar tenderness, maternal achondroplasia, Rh-incompatibility and pre-mature rupture of membrane (PROM), post term pregnancy belong to other group, each comprising 2\% [Table 1-3]

\section{Figure 5. Overall risk factors}

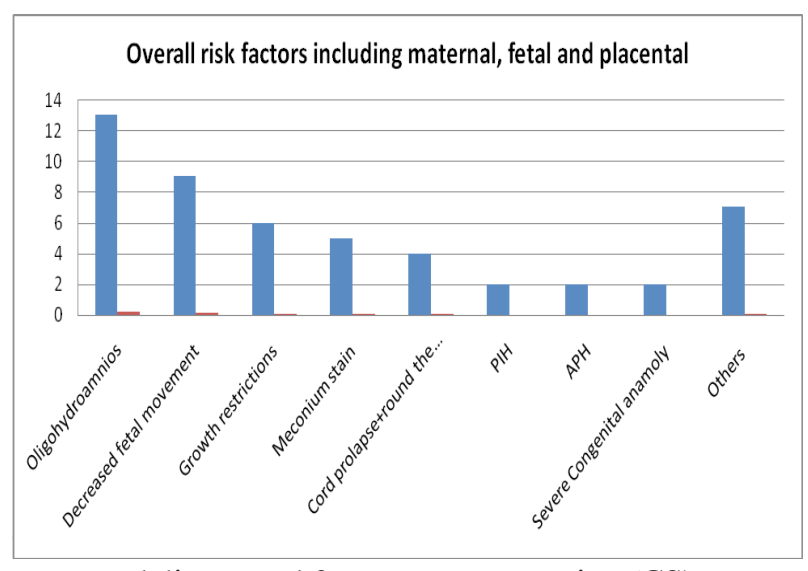

vacuum delivery and four caesarean section (CS).

\section{DISCUSSION}

The average stillbirth rate in the United States is approximately 1 in 160 births. $^{9}$ In our study the rate of stillbirth per thousand is 14.7 which was quite similar to the study by Shrestha et al. in 2010 in Patan Academy of Health Sciences, Patan Nepal. ${ }^{10}$ Stillbirth rate in our study was lower than the stillbirth rate of India (22 per thousand), Pakistan (43 per thousand $)^{11}$ and the national stillbirth rate 40 per thousand. ${ }^{10}$ In a community based study in Sarlahi districts of Nepal, Anne C. Lee et al.in 2010 found that the still birth rate in these rural area is 35.4 per 1000 births. ${ }^{12}$ According to the study, socioeconomic status, ethnicity are the key factors leading to stillbirths in rural areas. In our study group $38 \%$ cases were in low socioeconomic status among them $66 \%$ mothers living in rural areas. Increased in maternal age is another risk factors leading to stillbirths. Research conducted in Nepal and Bangladesh showed that older mothers above 30 years reported higher stillbirths than the younger mothers. ${ }^{13,14}$ Similarly, a hospital-based study conducted in Nigeria also revealed that mothers aged 35 years or older were significantly more likely to report higher rate of stillbirths. ${ }^{15}$ Our study comprised $28 \%$ (14) mothers above thirty years of age. Higher stillbirth rate in older women has been attributed to the increase likelihood of congenital anomalies, chronic hypertension, placenta previa, uterine rupture, and breech deliveries. ${ }^{12,16-18}$ 
This study showed that oligohydramnios is the leading cause for intrauterine death of fetus comprising of $26 \%$. Decreased amniotic volume in prenatal surveillance was associated with increased risk of deceleration in fetal heart beat, increased incidence of cesarean delivery for fetal distress, and lower APGAR scores. ${ }^{19-20}$

Decreased in fetal movement is another leading cause for stillbirth in our study comprising $18 \%$ of fetal death. ${ }^{21}$ Maternal perception of reduced fetal movements affects up to $15 \%$ of pregnancies arising concern and anxiety which can be associated with poor pregnancy outcome. ${ }^{22-23}$

Other major causes are growth restrictions, meconium staining and cord prolapse comprising of $12 \%, 10 \%$ and $8 \%$ respectively. Our study revealed that the average weight of stillborn babies was 2.1kilograms which was similar to study carried by McClure et $\mathrm{al}^{4}$ in 2006 . Besides other risk factor including thick amniotic fluid or meconium staining causes aspiration leading to fetal hypoxia and ultimately to intrauterine death. ${ }^{24}$ According to research from the Stillbirth Collaborative Research Network, umbilical cord accidents account for around 10 percent of stillbirths ${ }^{25}$ which is quite similar as in our study (8\%). Abnormal insertion of umbilical cord may lead to vasa previa. With furcated insertion of the umbilical cord, the umbilical cord blood vessels lose the protective cover of Wharton's substance before entering the chorionic plate. Owing to splaying of the vessels and their wide distribution, the vessels are exposed to external trauma. During labor and delivery, they may rupture, twist, and consequently compromise the placental circulation, resulting in stillbirth. ${ }^{26}$ Other associated risk factors concurred were PIH, APH, severe fetal congenital anomaly, maternal diseases and other factors which were the similar causes for still birth on another study. ${ }^{10,16}$ Ninety four percent of women enrolled in this study had attended hospital at least once for prenatal checkup. Sixty six percentage of women received more than 4 visits of ANC checkup which was similar to study revealed by Imtihaz et al. ${ }^{27} 6 \%$ of cases did not attend even a single ANC visit. Lack of ANC visit may be associated with increased risk of stillbirth. ${ }^{28}$

\section{CONCLUSION}

The major risk factors associated with stillbirths in Western Regional Hospital are oligohydramnios, decreased fetal movement, growth restrictions, meconium stain liquor, umbilical cord prolapse, antepartum hemorrhage, pregnancy induced hypertension, severe congenital anomaly, maternal chest infections, Rh-incompatibility, increased maternal age and post maturity.

No conflict of interest.

No human rights violation.

\section{FUNDING Nil.}

\section{REFERENCES}

1. Goldenberg RL, Thompson C. The infectious origins of stillbirth. Am J Obstet Gynecol. 2003; 189(3):861-73.

2. Lawn JE, Cousens S, Zupan J. 4 million neonatal deaths: when? Where? Why? Lancet. 2005; 365(9462):891-900

3. Ghimire PR, Agho KE, Renzaho A. Socio-economic predictors of stillbirths in Nepal (2001-2011). PLoS ONE. 2017; 12(7): e0181332.

4. Elizabeth M. McClure, Robert L. Goldenberg. Stillbirth in Developing Countries: A review of causes, risk factors and prevention strategies. Int J Gynecology Obstet. 2006;94:82-90

5. Joy Lawn, Kenji Shibuya, and Claudia Stein. No cry at birth: global estimates of intra partum stillbirths and intra partum-related neonatal deaths. Bull World Health Organ. 2005; 83(6):409-17.

6. KC Ashish, Johan Wrammert, Uwe Ewald et al. Incidence of intrapartum stillbirth and associated risk factors in tertiary care setting of Nepal: a case-control study. Reproductive Health. 2016;13:103

7. March of Dimes, PMNCH, Save the Children, World Health Organization (WHO). Born too soon: the global action report on preterm birth. Geneva: World Health Organization; 2012.

8. Lawn JE, Blencowe H, Pattinson R. Stillbirths: Where? When? Why? How to make the data count? Lancet. 2011; published online April 14. DOI:10.1016/S0140-6736(10)62187-3.

9. "Placental, pregnancy conditions account for most stillbirths" Archived 2013-08-01 at the Wayback Machine.U.S. Department of Health and Human Services. NIH News (December 13, 2011). Retrieved 2013-08-30.

10. Shrestha SR, Yadav BK. Risk factors associated with still births. J Nepal Med Assoc. 2010;49(177):84-7.

11. Stillbirth rates alarming in India, Pakistan. The Hans of India. Retrieved from http://www.thehansindia.com/posts/ index/Hans/2016-01-25/Stillbirth-rates-alarming-in-IndiaPakistan/202392

12. Lee AC, Mullany LC, Tielsch JM, Katz J, Khatry SK, LeClerg 
$\mathrm{SC}$, et al. Community-based stillbirth rates and risk factors in rural Sarlahi, Nepal. International Journal of Gynecology \& Obstetrics. 2011;113:199-204.

13. Ashish KC, Nelin V, Wrammert J, Ewald U, Vitrakoti R, Baral GN, et al. Risk factors for antepartum stillbirth: a case-control study in Nepal. BMC Pregnancy Childbirth. 2015;15:146 doi: 10.1186/s12884-015-0567-3

14. Nahar S, Rahman A, Nasreen HE. Factors influencing stillbirth in Bangladesh: a case-control study. Paediatric Perinatal Epidemiology. 2013;27:158-64.

15. Suleiman BM, Ibrahim HM, Abdulkarim N. Determinants of stillbirths in katsina, Nigeria: a hospital-based study. Paediatric reports. 2015;7:5615

16. Manandhar SR, Ojha A, Manandhar DS, Shrestha B, Shrestha D, Saville N, et al. Causes of stillbirths and neonatal deaths in Dhanusha district, Nepal: a verbal autopsy study. University Medical Journal. 2010;8:62-72.

17. Ministry of Health [Nepal], New ERA, and ORC Macro. 2002. Nepal Demographic and Health Survey 2001 Calverton, Maryland, USA: Family Health Division, Ministry of Health; New ERA; and ORC Macro.

18. Ministry of Health and Population (MOHP) [Nepal], New ERA, and Macro International Inc. 2007. Nepal Demographic and Health Survey 2006 Kathmandu, Nepal: Ministry of Health and Population, New ERA, and Macro International Inc.

19. Jorgensen AL, Alfirevic Z, Tudur Smith C, Williamson PR, Cerclage IPD Meta-analysis Group. Systemic review: Cervical stitch (cerclage) for preventing pregnancy loss: individual patient data meta-analysis. BJOG. 2007;114:1460

20. Ott WJ. Reevaluation of the relationship between amniotic fluid volume and perinatal outcome. Am J Obstet Gynecol. 2005; $192: 1803$
21. Unterscheider J, Horgan R, O’Donoghue K, Greene R. Reduced fetal movements. The Obstetrician \& Gynaecologist. 2009; 11:245-51

22. Sergent F, Lefevre A, Verspyck E, Marpeau L. Decreased fetal movements in the third trimester: what to do? Gynecol Obstet Fertil 2005; 33:861-9.

23. Heazell AE, Green M, Wright C, Flenady V, Froen JF. Midwives and obstetricians knowledge and management of women presenting with decreased fetal movements. Acta Obstet Gynecol Scand. 2008;87:331-9

24. Fetal hypoxia and meconium in pre term deliveries and stillbirth. D. Staribratova, V. Belovejdov. Trakia Journal of Sciences. 2011;9(2):45-8.

25. Stillbirth Collaborative Research Network Writing Group. "Causes of death among stillbirths." JAMA. 2011; 306(22):245968.

26. Reddy UM, Goldenberg R, Silver R, G. C. S., Pauli, R. M., Wapner, R. J et al. Stillbirth Classification-Developing an International Consensus for Research: Executive Summary of a National Institute of Child Health and Human Development Workshop. Obstetrics and gynecology. 2009;114(4):901-14.

27. JEHAN, Imtiaz; McCLURE, Elizabeth M; SALAT, Sohail; RIZVI, Sameera; PASHA, Omrana; HARRIS, Hillary et al. Neonatal mortality, risk factors and causes: a prospective population-based cohort study in urban Pakistan. Bull World Health Organ. 2009; 87(2):130-8.

28. Weiner R, Ronsmans C, Dorman E, Jilo H, Muhoro A, Shulman C. Labour complications remain the most important risk factors for perinatal mortality in rural Kenya. Bull World Health Organ. 2003;81(8):561-6. Epub 2003 Oct 14 